\title{
Improving the Acceptability of Internet-Based Cognitive-Behavioral Therapy Among Black Americans
}

\author{
Donovan M. Ellis and Page L. Anderson \\ Department of Psychology, Georgia State University
}

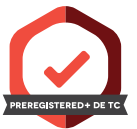

This experiment tested whether reading a treatment rationale using evidenced-based persuasion techniques increases the acceptability of therapist-assisted Internet-based cognitive behavioral therapies (iCBT) among Black individuals and explored whether self-reported barriers to treatment moderated this relation. The study also examined whether endorsement of iCBT by a health professional or spiritual leader is positively associated with attitudes toward iCBT. Participants $(N=268 ; n=139$, University; $n=129$, Community) were randomly assigned to read a treatment rationale for iCBT that used evidence-based persuasion techniques or a definition of iCBT that did not. Participants completed standardized self-report measures of treatment barriers and acceptability toward iCBT and rated their likelihood of using iCBT if endorsed by a health professional or spiritual leader. Participants reporting fewer barriers to treatment had more positive attitudes toward iCBT after reading a treatment rationale than those who read a definition. Participants reported a greater likelihood of using iCBT when endorsed by a health professional than by a spiritual leader or no authority figure. Participants recruited from the university reported more barriers to treatment than those recruited from the surrounding community. Future research is needed to replicate and better understand the use of persuasion techniques, authority figures, and differences in barriers to treatment between different communities in order to improve the acceptability of iCBT among Black Americans.

Keywords: Black American, iCBT, acceptability, treatment rationale, mental health barriers

Supplemental materials: https://doi.org/10.1037/tmb0000044.supp

Despite recent gains in mental health consciousness and resources, many Black Americans who could benefit from mental health treatment do not seek it (U.S. Department of Health and Human Services, 2001). Barriers to treatment seeking have been well documented among Black communities, ranging from prohibitive costs and transportation (Alegría et al., 2002; Snell-Johns et al.,
2004), to mental health stigma and a lack of faith in treatment efficacy (Ayalon \& Alvidrez, 2007; Gaston et al., 2016; Ward et al., 2013; Williams et al., 2012). Internet-based cognitive-behavioral therapies (iCBT) are mental health treatments delivered via the internet or other digital medium and are text based, often with the inclusion of video clips, audio files, and multimedia elements
Action Editor: Danielle S. McNamara was the action editor for this article. ORCID iDs: Donovan M. Ellis (DD https://orcid.org/0000-0002-98881613; Page L. Anderson (DD https://orcid.org/0000-0002-3811-9088.

Acknowledgements: We thank the Anxiety Research and Treatment Lab and every undergraduate assistant who worked tirelessly in their efforts to canvass the community and collect data for this project. This research was preregistered with the Open Science Framework (https://osf.io/2gyqx). The authors affirm that this was an IRB approved protocol and that there are no potential conflicts of interest to report.

Disclosures: The authors have no conflicts of interests to disclose.

Authors' Contributions: Donovan M. Ellis and Page L. Anderson devised the project, the main conceptual ideas and protocol outline. Donovan M. Ellis coordinated data collection for the study, conducted all statistical analyses, designed the figures and tables, and wrote the manuscript. Both Donovan M. Ellis and Page L. Anderson contributed to the final version of the manuscript. Page L. Anderson supervised the project.

Data Availability: Data from the present study has appeared in the following conference presentations.
Ellis, D. M. \& Anderson, P. L. (2019, November). Methods for improving the acceptability of therapist-assisted internet-based cognitive behavioral therapy among Black Americans [Poster presentation]. Poster presented at the 53rd Annual Convention for the Association for Behavioral and Cognitive Therapies (ABCT), Atlanta, GA.

Open Science Disclosures:

2. The preregistered design and analysis plan is accessible at https://doi.org/ 10.17605/OSF.IO/2GYQX

Open Access License: This work is licensed under a Creative Commons Attribution-NonCommercial-NoDerivatives 4.0 International License (CC-BYNC-ND). This license permits copying and redistributing the work in any medium or format for noncommercial use provided the original authors and source are credited and a link to the license is included in attribution. No derivative works are permitted under this license.

Contact Information: Correspondence concerning this article should be addressed to Page L. Anderson, Department of Psychology, Georgia State University, Urban Life Building, 11th Floor, 140 Decatur Street, Atlanta, GA 30303, United States. Email: panderson@gsu.edu 
(Andersson et al., 2014). iCBT has the potential to circumvent barriers identified by Black Americans, as they are cost effective (Gerhards et al., 2010; Hedman et al., 2011), do not require transportation, and can be done in the privacy of one's home, potentially addressing concerns of treatment-seeking stigma.

iCBT is, unfortunately, vastly underutilized by the general public, which has prompted research into its poor uptake (Carper et al., 2013; Hennemann et al., 2017; Waller \& Gilbody, 2009). Studies have noted that although there are advantages to using iCBT, there are disadvantages, too, such as concerns of confidentiality and lack of personal contact (Apolinário-Hagen et al., 2017; Choi et al., 2012; Schröder et al., 2015) and that people prefer face-to-face psychotherapy. However, research on iCBT among Black Americans is virtually nonexistent. The only study to explicitly examine attitudes toward iCBT among Black Americans (Jonassaint et al., 2017, 2020) found that, compared to Whites, Black participants were less likely to start and complete iCBT, although those who do complete report similar levels of improvement. A recent metaanalysis of randomized controlled trials investigating the efficacy and acceptability of iCBT (Andrews et al., 2018) supported the appeal and perceived benefits of iCBT, but the majority of studies (97\%) did not report the racial/ethnic make-up of their sample. Among studies that do report racial/ethnic demographics, there are very few Black participants, with most studies recruiting fewer than 10 Black participants (Choi et al., 2015; Lattie et al., 2019; Patel et al., 2018; Rosso et al., 2017). Only one study included a proportionate number of Black participants compared to population estimates (Forand et al., 2018). Thus, the literature on attitudes toward iCBT reflects the systemic pattern of Black underrepresentation in the psychological research (Cundiff, 2012). It is unknown how Black individuals feel toward iCBT. Given its potential to overcome barriers specifically documented for Black Americans, this is a critical gap in the literature.

Efforts to improve attitudes toward iCBT have drawn on the Unified Theory of Acceptance and Use of Technology (Venkatesh et al., 2003), which posits that performance expectancy (i.e., an individual's perception that technology will be beneficial) has the greatest impact on attitudes. Experimental studies show that providing a video explaining the rationale for iCBT significantly increased participants' feelings of credibility, expectancy-forimprovement, and likelihood of using iCBT among those reporting depressive symptoms, citing strong effect sizes $(d=.65$; Ebert et al., 2015; $r=-.56$; Mitchell \& Gordon, 2007; $\eta_{p}{ }^{2}=0.21$; Soucy et al., 2016). Casey et al. (2013) found that presenting even a brief, textbased educational component improved participants likelihood of using e-mental health services in the future. This work supports the Theory of Planned Behavior (Ajzen, 1991) which emphasizes the relationship among beliefs, attitudes, and behavioral intentions, with intentions being an immediate determinant of actual behavior and is consistent with research showing that mental health attitudes are predictive of treatment-seeking behaviors when examined both retrospectively (Beatie et al., 2016) and prospectively (Hammer \& Spiker, 2018). Each of these studies presumed that informing participants of the advantages of iCBT in reducing treatment barriers (e.g., cost, convenience) would lead to improved attitudes toward the intervention, especially among those who endorsed more barriers to face-to-face treatment. None of these studies, however, reported Black Americans in their samples. It is therefore unknown whether this popular method for improving acceptability of iCBT will be effective for Black Americans or if the impact will be different for Black people endorsing various barriers to traditional mental health treatment.

Research on treatment-seeking for in-person mental health treatment shows that Black Americans are less likely to seek specialty care due to cultural mistrust engendered by racism and mistreatment in the health care system (Cuevas et al., 2016; Whaley, 2001b, 2001a). Instead, Black Americans have historically sought information from a trusted institution that is associated with caregiving and coping among the Black community: The Church. The majority of Black Americans in the U.S. (87\%) belong to a religious group (Pew Research Center, 2009), and seeking informal advice and treatment for mental illness from clergy is both common and encouraged for many Black Americans (Avent et al., 2015; Blank et al., 2002; Taylor et al., 2004). Additionally, research has indicated that Black clergy hold more positive attitudes than previously assumed toward making referrals to mental health resources (secular or otherwise) when member distress is apparent (Payne, 2014; Young et al., 2003). Therefore, it may be possible to leverage the trusted authority of spiritual leaders and clergy persons to increase the acceptability of iCBT.

Similarly, Black Americans often visit their primary care physicians as their immediate link to health care (Schappert \& Burt, 2006). National surveys have indicated that less than half of Black respondents experiencing personal distress sought professional assistance for mental health problems (Neighbors, 1985; Neighbors et al., 2007). Black Americans who do obtain professional care are more likely to seek primary medical care than specialty mental health care (Neighbors, 1985; Neighbors et al., 2007; Snowden \& Pingitore, 2002). Medical professionals are thus an avenue for referral to mental health services. Recent research has found the prescription of iCBT by general practitioners to be an effective method for promoting the use and completion of these programs (Hobbs et al., 2018; Newby et al., 2017; Williams \& Andrews, 2013). Therefore, employing common helpseeking avenues used by Black Americans, such as medical and spiritual authority figures, may improve the attitudes, uptake, and utilization of iCBT.

\section{Present Study}

The purpose of this research is to identify strategies to increase acceptability of iCBT among Black Americans. This experimental study tests whether providing a rationale for iCBT that uses evidence-based persuasion techniques increases its acceptability among Black individuals. For the present study, acceptability was defined as a set of "cognitively based, positive attitudes toward these interventions" (Schröder et al., 2015, p. 137). This contrasts with previous studies defining acceptability as a construct of treatment satisfaction. The study also examines whether referral by a medical or spiritual authority figure is associated with increased likelihood of using iCBT. Based on prior literature, we hypothesized the following:

$H$ (1): Participants who read a treatment rationale for iCBT will report greater acceptability compared to those who read a definition of iCBT.

$H$ (2): Participants reporting more barriers to mental health treatment will report greater acceptability of iCBT. 
$H$ (3): Barriers to mental health treatment will moderate the effect of a treatment rationale on acceptability of iCBT such that there will be a stronger positive relation between receiving a rationale and acceptability of iCBT among participants reporting more barriers.

$H$ (4): Participants will report being more likely to use iCBT if recommended by a spiritual leader or if prescribed by a health professional as compared to no recommendation.

\section{Method}

\section{Participants}

Participants were self-identified Black/African American adults $(N=268)$. To be eligible, participants had to be at least 18 years of age and fluent in English, evidenced by completion of the informed consent form (Flesch-Kincaid 7th grade reading level). Undergraduate participants ( $n=139)$ were recruited from a large, urban, southeastern university and received course credit for their participation. Community participants $(n=129)$ were recruited in public places throughout the surrounding metropolitan area (e.g., parks) and had the opportunity to enter a raffle with a 1 in 30 chance of winning a $\$ 25$ Amazon gift card. The participants ranged in age from 18 to $85(M=27.59, S D=13.58)$, were predominantly female $(67 \%)$ and highly educated $(70 \%$ have some college education). Table 1 shows participants' demographic characteristics.
An a-priori power analysis was conducted based on the work of Ebert et al., (2015). Because this study used a video-based treatment rationale to increase acceptability, a more conservative effect size $\left(\eta^{2}=0.03\right)$ was adopted for the present study's text-based treatment rationale. A sample size of $N=260$ was determined to be sufficiently powered (.80) to test the hypotheses.

\section{Measures}

Participants completed a survey developed and hosted on the Qualtrics online survey platform. The survey included the following measures:

\section{Treatment Acceptability}

Attitudes Toward Psychological Online Interventions Scale (APOI; Schröder et al., 2015) is a 16-item validated measure of attitudes toward online psychological interventions that, for the purposes of the current project, was modified to reference therapistassisted iCBT. The APOI comprises four subscales measuring attitudes toward psychological online interventions: "Skepticism and Perception of Risk," "Confidence in Effectiveness," "Technologization Threat," and "Anonymity Benefits." Participants rate their agreement with each item (e.g., "I have the feeling that iCBT can help me.") on a five-point Likert scale ( 1 = Totally agree to $5=$ Totally disagree). Although not indicated in original paper (Schröder et al., 2015), positively valenced items should be reverse

Table 1

Demographic Characteristics for Participants Recruited From the University Participant Pool and From the Surrounding Community for Each Experimental Condition

\begin{tabular}{|c|c|c|c|c|c|c|}
\hline \multirow[b]{2}{*}{ Demographics } & \multirow[b]{2}{*}{ Participants' characteristics } & \multicolumn{2}{|c|}{$\begin{array}{l}\text { Rationale condition } \\
n=115(\%)\end{array}$} & \multicolumn{2}{|c|}{$\begin{array}{c}\text { Definition condition } \\
n=153(\%)\end{array}$} & \multirow[b]{2}{*}{$\begin{array}{c}\text { Total } \\
N=268(\%)\end{array}$} \\
\hline & & $\begin{array}{c}\text { University } \\
\text { participants } \\
N=64(\%)\end{array}$ & $\begin{array}{l}\text { Community } \\
\text { participants } \\
N=51(\%)\end{array}$ & $\begin{array}{c}\text { University } \\
\text { participants } \\
N=75(\%)\end{array}$ & $\begin{array}{l}\text { Community } \\
\text { participants } \\
N=78(\%)\end{array}$ & \\
\hline Age & $M_{\text {Age }}(S D)$ & $20.0(3.8)$ & $37.5(16.0)$ & $20.6(5.4)$ & $33.9(15.2)$ & $27.59(13.6)$ \\
\hline \multirow[t]{3}{*}{ Sex } & Male & $9(14.1)$ & $13(25.5)$ & $19(25.3)$ & $46(59.0)$ & $87(32.5)$ \\
\hline & Female & $54(85.9)$ & $37(72.5)$ & $56(74.7)$ & $32(41.0)$ & $179(66.8)$ \\
\hline & Did not disclose & $1(1.6)$ & $1(2.0)$ & $0(0.0)$ & $0(0.0)$ & $2(0.4)$ \\
\hline \multirow[t]{4}{*}{ Sexual identity } & Heterosexual & $56(87.5)$ & $44(86.3)$ & $64(85.3)$ & $58(74.4)$ & $222(82.8)$ \\
\hline & Lesbian, gay, bisexual & $8(12.5)$ & $5(9.8)$ & $11(14.7)$ & $14(17.9)$ & $38(14.2)$ \\
\hline & Self-identify & $0(0.0)$ & $2(3.9)$ & $0(0.0)$ & $4(5.1)$ & $6(2.2)$ \\
\hline & Did not disclose & $0(0.0)$ & $0(0.0)$ & $0(0.0)$ & $2(2.6)$ & $2(0.7)$ \\
\hline \multirow[t]{5}{*}{ Current education status } & High school & $0(0.0)$ & $0(0.0)$ & $0(0.0)$ & $1(1.3)$ & $1(0.4)$ \\
\hline & Some college/currently in college & $63(98.4)$ & $15(29.4)$ & $72(96.0)$ & $26(33.3)$ & $176(65.7)$ \\
\hline & Graduate/professional degree & $1(1.6)$ & $3(5.9)$ & $0(0.0)$ & $2(2.6)$ & $6(2.2)$ \\
\hline & Nondegree student/Other & $0(0.0)$ & $0(0.0)$ & $3(4.0)$ & $1(1.3)$ & $4(1.5)$ \\
\hline & Nonstudent $^{\mathrm{a}}$ & $0(0.0)$ & $33(64.7)$ & $0(0.0)$ & $48(61.5)$ & $81(30.2)$ \\
\hline \multirow[t]{6}{*}{ Religiosity } & Very important & $26(40.6)$ & $27(52.9)$ & $31(41.3)$ & $38(48.7)$ & $122(45.5)$ \\
\hline & Important & $19(29.7)$ & $11(21.6)$ & $26(34.7)$ & $18(23.1)$ & $74(27.6)$ \\
\hline & Neutral & $13(20.3)$ & $7(13.7)$ & $11(14.7)$ & $16(20.5)$ & $47(17.5)$ \\
\hline & Unimportant & $3(4.7)$ & $3(5.9)$ & $5(6.7)$ & $6(7.7)$ & $17(6.3)$ \\
\hline & Very unimportant & $3(4.7)$ & $0(0.0)$ & $2(2.7)$ & $0(0.0)$ & $5(1.9)$ \\
\hline & Did not disclose & $0(0.0)$ & $3(5.9)$ & $0(0.0)$ & $0(0.0)$ & $3(1.1)$ \\
\hline \multirow[t]{6}{*}{ Relationship status } & Single & $45(70.3)$ & $29(56.9)$ & $45(60.0)$ & $53(67.9)$ & $172(64.2)$ \\
\hline & Serious dating or committed relationship & $16(25.0)$ & $7(13.7)$ & $23(30.7)$ & $11(14.1)$ & $57(21.3)$ \\
\hline & Civil union, domestic partnership or equivalent & $0(0.0)$ & $2(3.9)$ & $0(0.0)$ & $0(0.0)$ & $2(0.7)$ \\
\hline & Married & $3(4.7)$ & $4(7.8)$ & $3(4.0)$ & $7(9.0)$ & $17(6.3)$ \\
\hline & Separated/divorced/widowed & $0(0.0)$ & $9(17.6)$ & $2(2.7)$ & $7(9.0)$ & $18(6.7)$ \\
\hline & Did not disclose & $0(0.0)$ & $0(0.0)$ & $2(2.7)$ & $0(0.0)$ & $2(0.7)$ \\
\hline
\end{tabular}

\footnotetext{
${ }^{a}$ Reflects current noneducational status but does not indicate highest level of education completed (i.e., may include college graduates).
} 
coded (J. Schröder, personal communication, February 12, 2020). Total scores range from 16 to 80 with higher scores indicating more positive attitudes toward iCBT. The APOI demonstrated high overall internal consistency $(\alpha=.77)$ in a sample of 1,013 German-speaking participants (Schröder et al., 2015). The APOI was used as the primary measure for acceptability of iCBT and demonstrated excellent internal consistency in the present sample $(\alpha=.89)$.

\section{Barriers to Treatment}

Perceived Barriers to Psychological Treatment Scale (Mohr, Ho, et al., 2010). The Perceived Barriers to Psychological Treatment Scale (PBPT) is a self-report measure of the extent to which participants perceive barriers to seeking mental health treatment. It comprises 25 items divided into eight subscales (25 items, $\alpha=$ .71-.89). Past research shows that, compared to White participants, African Americans report greater scores on the following subscales: Stigma (discomfort with seeking psychological treatment due to fears of judgment from others and oneself), Participation Restrictions (physical and logistical barriers to treatment), and Availability of Services (general accessibility and awareness of resources; Mohr, Ho, et al., 2010), indicating that these are particularly salient barriers that need to be addressed.

Responses are scored on a five-point Likert scale $(1=$ Not difficult at all to $5=$ Impossible) ranging from 25 to 125 . If any item is rated as "extremely difficult" or "impossible," then the respective subscale can be labeled as a "substantial barrier," regardless of the scores on other items of the subscale (Mohr et al., 2006). The PBPT was validated on a large sample of primary care patients $(N=658)$ representing a diverse ethnic demographic, and the measure and its subscales demonstrate good to excellent reliability ( $\alpha=$.71-.89; Mohr, Ho, et al., 2010). The PBPT demonstrated excellent internal consistency in the present sample $(\alpha=.92)$.

\section{Participant Characteristics}

Demographics Questionnaire. A 22-item demographics questionnaire was developed for the present study using items from the Standardized Data Set from the Center for Collegiate Mental Health at Penn State University (Center for Collegiate Mental Health, 2017). These questions were developed with input from over 100 college counseling centers in the U.S. describing approximately 150,000 university students seeking mental health treatment and assessed age, sex, sexual orientation, education, finances, relationship status, and religious/spiritual preference.

Depression, Anxiety, and Stress Scale-21 Item (Lovibond \& Lovibond, 1993). The Depression, Anxiety, and Stress Scale-21 (DASS-21) is a validated measure of psychological symptoms comprised of three subscales: Depression, anxiety, and stress. Participants rate each item on a four-point Likert scale, and scores range from 0 to 126, with higher scores indicating greater distress. The DASS-21 was normed on a nonclinical sample, and it shows good psychometric properties across racial groups, including among African Americans (Norton, 2007). The DASS-21 demonstrated excellent internal consistency in the present sample $(\alpha=.92)$. The DASS-21 is positively correlated with rates of treatment seeking (Magaard et al., 2017).

Mental Health Treatment Experience. Participants' experience using both face-to-face and internet-based mental health services was measured using a series of Likert-type self-report items developed for this study (e.g., "Have you ever received face-to-face psychotherapy or counseling?," "If so, how helpful were these services"). Questions solicited information regarding both past and current experiences with mental health treatment.

\section{Procedure}

Participants were recruited by undergraduate and graduate research assistants canvassing public locations (i.e., parks) throughout the metropolitan area and from the university participant pool. Undergraduate participants enrolled for course credit were provided access to the survey link to complete the study at their leisure on their own personal web-enabled devices. All data were collected online and will be made available upon reasonable request. This study was conducted in compliance with the university Institutional Review Board Protocol \#H18341 and preregistered with the Open Science Framework (https://osf.io/2gyqx; Ellis \& Anderson, 2020).

Following informed consent, all participants were randomly assigned via Qualtrics (1:1 allocation) to read either a treatment rationale or a definition of iCBT, eliminating the possibility of experimenter bias. Participants completed questionnaires assessing demographic information, symptoms of depression, anxiety, and stress, and barriers to psychological treatment. Participants then read about iCBT, the content of which varied according to experimental condition (described below), completed the questionnaire on attitudes toward iCBT (APOI) and indicated their likelihood of using iCBT if recommended/prescribed by an authority figure or not.

\section{Experimental Condition: Treatment Rationale}

Participants who were randomly assigned to read a text-based treatment rationale received a description of iCBT, a brief summary of research evidence supporting the efficacy of such treatments, and a Frequently Asked Questions (FAQ) section designed to ease common concerns about iCBT based on the literature (Travers \& Benton, 2014; see Supplemental Materials S1 for details). The treatment rationale uses evidence-based persuasion techniques as outlined by Cialdini (2006), including leveraging the appeal of authority figures (rationale is presented by a White, middle-aged, female licensed clinical psychologist) and social proof (assuring the reader that iCBT programs are used and effective). An explanation of technical language (e.g., iCBT) was also incorporated, as it has been shown to increase confidence in psychotherapy (Constantino et al., 2012). After being provided the treatment rationale, each participant answered three questions about iCBT, which served as a manipulation check ensuring that participants read and understood the treatment rationale. This treatment rationale was designed as part of a larger study (Molloy et al., 2021) incorporating elements of persuasion that could be delivered in a text/image format to a diverse audience.

Participants not assigned to receive a rationale were provided a brief definition of internet-delivered, cognitive-behavioral therapies (See Supplemental Materials S2 for details).

\section{Analytic Plan}

H (1) An Analysis of Covariance (ANCOVA) was proposed to test the hypothesis that participants who receive a treatment rationale would report greater acceptability of iCBT compared to those 
who do not receive a rationale (https://osf.io/2gyqx). This analysis was modified to a $2 \times 2$ ANCOVA (Rationale $\times$ Recruitment Source with DASS-21 as covariate) to account for the potential influence of participant recruitment source. Some proposed covariates were not used due to experimenter error in data collection.

H (2) Pearson's r correlations were proposed to test the hypothesis that participants' self-reported barriers to mental health treatment (PBPT) would be positively related to acceptability of iCBT (APOI).

$\mathrm{H}$ (3) Multiple regression analyses were proposed to examine the moderating effect of barriers to treatment (PBPT) on the relationship between the treatment rationale (yes, no) and self-reported acceptability (APOI) toward iCBT. First Block: Covariates-mental health symptomatology (DASS-21). Second Block: Treatment rationale (yes/no) and perceived barriers to treatment (i.e., stigma, participant restrictions, and availability of services). Third Block: Interaction effects - treatment rationale $\times$ barriers to treatment.

$H$ (4): Paired samples $t$-tests were originally proposed to examine whether there was a significant difference between participants' selfreported willingness to use $\mathrm{iCBT}$ and the type of authority figure making the endorsement for iCBT (i.e., health professional vs. spiritual leader). This analysis was modified to a Repeated Measures Analysis of Variance (ANOVA) to account for a third level of the independent variable (i.e., ratings made based on no authority endorsement at all).

\section{Results}

Participants who did not answer all three questions assessing comprehension of the treatment rationale correctly (which served as a manipulation check; $n=41$ ) or who completed the survey under 5 min $(n=1)$ were excluded from data analyses to maximize internal validity, resulting in a sample of $N=268$ (University = 139 ; Community $=129$ ). University participants were $2.77,95 \% \mathrm{CI}$ $[1.30,5.92]$ times more likely to pass the manipulation check than community participants.

\section{Descriptive Statistics}

Table 1 shows a variety of participant characteristics within the sample. Most participants self-identified as female (67\%), heterosexual $(83 \%)$, single $(64 \%)$, and reported that religion was important to them $(73 \%)$. Participants recruited from the university participant pool were, by definition, currently in college. Almost a third of participants recruited from the community was currently in college or had a professional degree, but, because of an error in data collection, it is not known what proportion had graduated from college.

There were no differences between the experimental conditions on any of the key variables, including attitudes toward iCBT, depressive and anxious symptom severity, nor barriers to treatment (all $p$ 's > .05). As shown in Table 2, relative to participants recruited from the community, participants recruited from the university reported they had more barriers to treatment $(M$ diff $=6.63$, $t$-score $=3.45, p=.001)$. Over one third $(36 \%)$ of participants recruited from the community reported receiving therapy, compared to $25 \%$ of participants recruited from the university, although this difference was not significant $(p=.05)$.

Table 3 shows the means, standard deviations, and intercorrelations for key variables. Less than half the sample (44.6\%) indicated they would "likely" or "definitely" use an iCBT with $1.3 \%$ of participants having used an online mental health program in the past. Responses to the Depression, Anxiety, and Stress Scale-21 indicated that participants did not endorse clinical levels of mental health symptoms $(M=29.90, S D=21.06)$ based on the suggested cutoff of 60 for severe mental illness (Lovibond \& Lovibond, 1995).

As suggested by the authors (Mohr et al., 2006), each item on the Perceived Barriers to Psychological Treatment Scale was classified as a "substantial barrier" (i.e., "extremely difficult" or "impossible") or not. The majority of participants $(59.9 \%)$ reported at least one substantial barrier, $43.5 \%$ endorsed at least two substantial barriers, and $31.6 \%$ of participants endorsed three or more substantial barriers to psychological treatment. As shown in Table 4, "cost of psychotherapy" was the most frequently reported substantial barrier to treatment (39.2\% of participants). Average scores on the subscales of the PBPT are as follows: Total score $(M=42.71, S D=15.08)$, Stigma $(M=11.87, S D=5.48)$, Participation Restrictions $(M=5.59, S D=2.35)$, and Availability of Services $(M=3.99, S D=2.13)$.

\section{Does Using a Treatment Rationale Lead to Greater Acceptance of iCBT?}

A $2 \times 2$ ANCOVA (Rationale $\times$ Recruitment Source with DASS21 as covariate) was conducted examining the effect of treatment rationale for participants recruited from the university and surrounding community on attitudes of acceptability toward iCBT while controlling for depression and anxiety symptom severity. There was not a significant two-way interaction between receiving the treatment rationale and recruitment source, $F(1,220)=0.09, p=.76$, partial $\eta^{2}<0.001$, nor a main effect of recruitment source, $F(1$, $220)=0.002, p=.96$, partial $\eta^{2}<0.01$, on attitudes of acceptability toward iCBT. Contrary to the hypothesis, there was not a main effect of treatment rationale, $F(1,220)=2.35, p=.13$, partial $\eta^{2}=0.01$ on attitudes of acceptability toward iCBT.

\section{Do Participants Who Report More Barriers to Treatment Show Greater Acceptance of iCBT?}

Pearson's $r$ correlations tested the hypothesis that the number of self-reported barriers to mental health treatment would be related to more positive attitudes toward iCBT. Contrary to hypotheses, there was no relation between acceptability of iCBT and the total number of barriers, $r(219)=-.09, p=.18$, nor the stigma, $r(231)=-.08$, $p=.21$, participant restrictions $r(231)=-.08, p=.24$, or availability of services subscales, $r(231)=-.01, p=.91$.

\section{Do Treatment Barriers Moderate the Relation Between Receiving a Treatment Rationale and Acceptance of iCBT?}

A series of multiple hierarchical regressions using bias-corrected 95\% confidence intervals calculated from 5,000 bootstrapped samples with the SPSS PROCESS macro (Hayes, 2018) was used to test the hypothesis that barriers to treatment moderates the relation between receiving a treatment rationale and attitudes toward iCBT. This analysis was conducted separately for the barriers to treatment total score, as well as the stigma, participant restrictions, and availability of services subscale scores. For each regression, recruitment source (university, community) and depression and anxiety symptom severity (DASS-21) were entered in the first 
Table 2

Measures of Acceptability of iCBT, Symptoms of Depression and Anxiety, and Barriers to Treatment Across Participants Recruited From the University and the Community and by Experimental Group

\begin{tabular}{|c|c|c|c|c|c|c|c|c|c|c|}
\hline \multirow[b]{2}{*}{ Scale } & \multirow{2}{*}{$\begin{array}{c}\begin{array}{c}\text { University } \\
\text { participants }\end{array} \\
M(S D) / \text { Ratio }\end{array}$} & \multirow{2}{*}{$\frac{\begin{array}{c}\text { Community } \\
\text { participants }\end{array}}{M(S D) / \text { Ratio }}$} & \multicolumn{3}{|c|}{$\begin{array}{c}\text { Group } \\
\text { differences }\end{array}$} & \multirow{2}{*}{$\begin{array}{c}\begin{array}{c}\text { Rationale } \\
\text { condition }\end{array} \\
M(S D) / \text { Ratio }\end{array}$} & \multirow{2}{*}{$\begin{array}{c}\begin{array}{c}\text { Definition } \\
\text { condition }\end{array} \\
M(S D) / \text { Ratio }\end{array}$} & \multicolumn{3}{|c|}{$\begin{array}{c}\text { Group } \\
\text { differences }\end{array}$} \\
\hline & & & $t$-score $/ \chi 2$ score & $d f$ & $p$ & & & $t$-score $/ \chi 2$ score & $d f$ & $p$ \\
\hline APOI & $50.54(6.50)$ & $50.85(5.98)$ & 0.37 & 232 & .709 & $51.32(6.70)$ & $50.22(5.93)$ & 1.33 & 232 & .186 \\
\hline DASS & $31.80(20.37)$ & $27.80(21.70)$ & 1.51 & 252 & .132 & $31.87(21.27)$ & $28.45(20.86)$ & 1.28 & 252 & .202 \\
\hline PBPT & $45.79(15.43)$ & $39.16(13.90)$ & 3.45 & 235 & .001 & $43.55(14.84)$ & $42.14(15.27)$ & 0.71 & 235 & .48 \\
\hline
\end{tabular}

Note. University participants $(N=127-139)$ and community participants $(N=110-125)$ depending on the pattern of data missingness. APOI $=$ attitudes toward psychological online interventions scale (therapist assisted); DASS = depression, anxiety, and stress scale; PBPT = perceived barriers to psychological treatment scale; iCBT = Internet-based cognitive behavioral therapies.

step, treatment rationale (yes, no) and barriers to treatment were entered in the second step, and the interaction between treatment rationale and barriers to treatment was entered in the third step.

As hypothesized, there was a significant interaction between treatment rationale and barriers to treatment for the total scale score, $\Delta R^{2}=.06, F(1,205)=12.70, p<.001, b=-.21,95 \%$ CI $[-.32$, -.09], $t(204)=-3.56, p<.001$ and for the stigma subscale score, $\Delta R^{2}=.06, F(1,226)=14.67, p<.001, b=-.57,95 \%$ CI $[-.87$, $-.28], t(217)=-3.83, p<.001$. There was not, however, a significant interaction between receiving a treatment rationale and the participant restrictions subscale score, $\Delta R^{2}=.01, F(1,216)=$ $2.40, p=.12$, nor the availability of services subscale score, $\Delta R^{2}=.01, F(1,216)=2.79, p=.10$.

Simple slope analyses (unstandardized $\beta$ coefficients) tested the nature of the significant interactions and showed that compared to the no rationale condition, participants who received a rationale reported more favorable attitudes toward iCBT, but, unexpectedly, this was only among those participants who reported fewer total barriers, (1 SD below mean), $b=4.51,95 \%$ CI [2.06, 6.97], $t(205)$ $=3.62, p=<.001$. There was no difference in attitudes toward iCBT after receiving a treatment rationale among participants reporting average (at the mean), $b=1.40,95 \% \mathrm{CI}[-.29,3.10], t(205)=1.63$, $p=.10$ or higher levels of total barriers (1 SD above mean),

\section{Table 3}

Means, Standard Deviations, and Correlations Between Attitudes Toward Internet-Based Cognitive-Behavior Therapy, Symptoms of Depression and Anxiety, Barriers to Treatment, and History of Face-to-Face Treatment

\begin{tabular}{lcccc}
\hline \multicolumn{1}{c}{ Variable } & 1 & 2 & 3 & 4 \\
\hline 1. Attitudes toward iCBT (APOI) & $(.89)$ & & & \\
2. DASS & -0.09 & $(.92)$ & & \\
3. PBPT & -0.09 & $0.61^{* *}$ & $(.92)$ & \\
4. Tx Hx & -0.03 & $0.15^{*}$ & .10 & - \\
$M$ & 50.67 & 29.90 & 7.52 & 42.71 \\
$S D$ & 6.27 & 21.06 & 8.58 & 15.08 \\
Range & $33-80$ & $0-104$ & $25-94$ & - \\
\hline
\end{tabular}

Note. $\quad N=219-237$ depending on the pattern of data missingness. Entries on the main diagonal are Cronbach's $\alpha$. APOI $=$ Attitudes toward psychological online interventions; DASS $=$ depression and anxiety symptom severity; PBPT = perceived barriers to psychological treatment; Tx Hx = history of face-to-face treatment (yes, no); iCBT = Internet-based cognitive behavioral therapies.

$* p<.05$. ** $p<.001$. $b=-1.71,95 \%$ CI $[-4.08, .67], t(205)=-1.42, p=.16$ (see Figure 1). An identical pattern was found for stigma subscale scores: Compared to the no rationale condition, participants who received a treatment rationale reported more positive attitudes toward iCBT if they endorsed relatively low levels of stigma, $b=4.38,95 \%$ CI $[2.12,6.64], t(217)=3.82, p=<.001$, but not at average or higher levels of stigma; $b=1.49,95 \%$ CI [-.16, $3.14], t(217)=1.78, p=.08$ and $b=-1.73,95 \%$ CI [-4.03, .57], $t(217)=-1.48, p=.14$, respectively (see Figure 2 ).

The effects of recruitment source and depression and anxiety symptom severity were nonsignificant in all models.

\section{Does Endorsement From an Authority Figure Increase the Likelihood of Using iCBT?}

Repeated measures ANOVA tested the hypothesis that participants would report being more likely to use iCBT if recommended by a spiritual authority figure or if prescribed by a health professional relative to no endorsement by an authority figure. Mauchly's test, $\chi^{2}(2)=10.26, p=.006$, indicated a violation of sphericity, therefore a Greenhouse-Geisser correction was applied $(\varepsilon=0.96)$. Results indicated a significant main effect, $F(1.92,468.62)=23.09$, $p<.001, \eta_{p}{ }^{2}=.09$. Bonferroni-corrected pairwise comparisons showed that participants were more likely to use iCBT if prescribed by a health professional $(M=3.62, S D=1.13)$ than if referred by a spiritual leader $(M=3.26, S D=1.16 ; M$ difference $=.36$, $p<.001)$, or in the absence of an endorsement by an authority figure $(M=3.29, S D=1.12 ; M$ difference $=.32, p<.001)$. Participants reported being no more likely to use iCBT if referred by a spiritual leader than in the absence of an endorsement by an authority figure $(M$ difference $=.04, p>.05)$.

\section{Discussion}

Overall, the results of this study did not support hypotheses: Providing a treatment rationale did not improve acceptability toward iCBT and there was not a direct positive relation between barriers to treatment and acceptability of iCBT. Barriers to treatment did moderate the relation between a treatment rationale and acceptability toward iCBT, although in an unanticipated direction, in that the rationale only improved attitudes toward iCBT among people reporting fewer barriers to treatment. Finally, the recommendation of spiritual leader was not associated with a greater likelihood of using iCBT, but the prescription of a health professional was. 
Table 4

Percentage of Participants Reporting That an Item on the Perceived Barriers to Psychological Treatment Scale was a "Substantial" Barrier (as Recommended by the Authors of the Scale; Mohr et al., 2006)

\begin{tabular}{lccr}
\hline \multicolumn{1}{c}{ Barrier } & $\begin{array}{c}\text { University } \\
n(\% \text { Endorsed })\end{array}$ & $\begin{array}{c}\text { Community } \\
n \text { (\% Endorsed) }\end{array}$ & $\begin{array}{c}\text { Total } \\
\text { (\% Endorsed) }\end{array}$ \\
\hline 1. Cost of psychotherapy & $63(45.3)$ & $42(32.6)$ & $105(39.2)$ \\
2. Interference from daily responsibilities & $34(24.5)$ & $15(11.6)$ & $49(18.3)$ \\
3. Don't know how to find counselor/therapist & $28(20.1)$ & $15(11.6)$ & $43(16.0)$ \\
4. Difficulties getting time off work & $27(19.4)$ & $11(8.5)$ & $38(14.2)$ \\
5. Being seen while emotional & $26(18.7)$ & $8(6.2)$ & $34(12.7)$ \\
6. Discomfort talking to someone I don't know & $21(15.1)$ & $11(8.5)$ & $32(11.9)$ \\
7. My problems are not bad enough & $19(13.7)$ & $12(9.3)$ & $31(11.6)$ \\
8. Problems with transportation & $17(12.2)$ & $12(9.3)$ & $29(10.8)$ \\
9. Lack of available counseling/psychotherapy & $18(12.9)$ & $11(8.5)$ & $29(10.8)$ \\
10. Concerns about documentation in insurance & $19(13.7)$ & $8(6.2)$ & $27(10.1)$ \\
11. Concerns about being judged & $17(12.2)$ & $7(5.4)$ & $24(9.0)$ \\
12. Lack of energy or motivation & $13(9.4)$ & $8(6.2)$ & $21(7.8)$ \\
13. Difficulty motivating self & $14(10.1)$ & $5(3.9)$ & $19(7.1)$ \\
14. Counseling means I can't solve problems myself & $15(10.8)$ & $4(3.1)$ & $19(7.1)$ \\
15. Stigma of family/friends knowing & $14(10.1)$ & $4(3.1)$ & $18(6.7)$ \\
16. Would not expect counseling to be helpful & $11(7.9)$ & $6(4.7)$ & $17(6.3)$ \\
17. Attending counseling would feel self-indulgent & $10(7.2)$ & $6(4.7)$ & $16(6.0)$ \\
18. Concerns about upsetting feelings in counseling & $9(6.5)$ & $7(5.4)$ & $16(6.0)$ \\
19. Counselor would not care about me & $7(5.0)$ & $8(6.2)$ & $15(5.6)$ \\
20. Distrust counselors & $5(3.6)$ & $8(6.2)$ & $13(4.9)$ \\
21. Talking about problems makes them worse & $9(6.5)$ & $3(2.3)$ & $12(4.5)$ \\
22. Difficulty walking or getting around & $6(4.3)$ & $3(2.3)$ & $9(3.4)$ \\
23. Bad experiences with counselors & $4(2.9)$ & $5(3.9)$ & $9(3.4)$ \\
24. Physical symptoms (fatigue, pain, breathing problems) & $3(2.2)$ & $5(3.9)$ & $8(3.0)$ \\
25. Illness making it hard to leave home & $5(3.6)$ & $1(0.8)$ & $6(2.2)$ \\
\hline & University & Community & Total \\
\hline & $n(\%$ Endorsed) & $n(\%$ Endorsed) & $n(\%$ Endorsed) \\
\hline Number of barriers & $45(35.4)$ & $50(45.5)$ & $95(40.1)$ \\
1 & $16(12.6)$ & $23(20.9)$ & $39(16.5)$ \\
2. & $16(12.6)$ & $12(10.9)$ & $28(11.8)$ \\
3+ & $50(39.4)$ & $25(22.7)$ & $75(31.6)$ \\
\hline
\end{tabular}

Note. $\quad N=268$. Barriers rated as "extremely difficult" or "impossible are classified as "substantial barriers" (Mohr et al., 2006). Percentages do not total $100 \%$ as participants may rate more than one barrier as being "substantial".

These null results contradict previous studies, which demonstrated the positive impact of presenting a treatment rationale or psychoeducation on participants' feelings of credibility, expectancy-for-improvement, and likelihood of using iCBT (Ebert et al., 2015; Mitchell \& Gordon, 2007; Soucy et al., 2016). One reason for this null result may be the construction of the treatment rationale itself. The length of the presented rationale was approximately 800 words. Some research has indicated that although rationale content is important, length does matter, with shorter descriptions (approximately 250 words) more effective for enhancing expectations of therapeutic success (Horvath, 1990).

In line with previous research, participants in this study endorsed several barriers to mental health treatment with cost being a substantial impediment for $40 \%$ of the sample. Furthermore, $43 \%$ of participants reported more than one substantial barrier to treatment reflecting both structural and attitudinal obstacles to face-toface therapy. Therefore, the lack of relation between barriers to treatment and attitudes toward therapist-assisted iCBT was surprising given the oft-touted benefits of using iCBT to circumvent barriers such as cost, stigma, and treatment availability. Indeed, participants frequently endorse advantages of iCBT in reducing stigma, lack of motivation, availability, and cost of treatment (Choi et al., 2015; Travers \& Benton, 2014), despite expressing an overall preference for face-to-face therapy over internet-based therapy. This may reflect nomothetic appraisals for the benefits of iCBT in general, but an individual preference to engage in traditional therapy when addressing personal mental health concerns. Another possible explanation is that barriers to traditional mental health treatment may also apply to iCBT. This may be especially true for attitudinal barriers. For example, stigma-related concerns of "being judged" or "counseling means I can't solve problems myself" may equally hinder participants regardless of whether they are seeking a therapist in-person or via the internet. Indeed, previous research has indicated that although Black Americans are more likely to face structural and logistical barriers (e.g., cost and transportation) in the pursuit of therapy (Alegria et al., 2012; Snell-Johns et al., 2004), attitudinal and evaluative barriers toward psychotherapy often prove to be the biggest obstacle (Mojtabai et al., 2011; Sareen et al., 2007). One's impression of the cost and convenience benefits of iCBT may be muted by attitudinal barriers, such as stigma. 
Figure 1

Line Graph Indicating That Overall Barriers to Psychological Treatment Moderates the Relationship Between Treatment Rationale and Acceptability Toward Therapist-Assisted iCBT

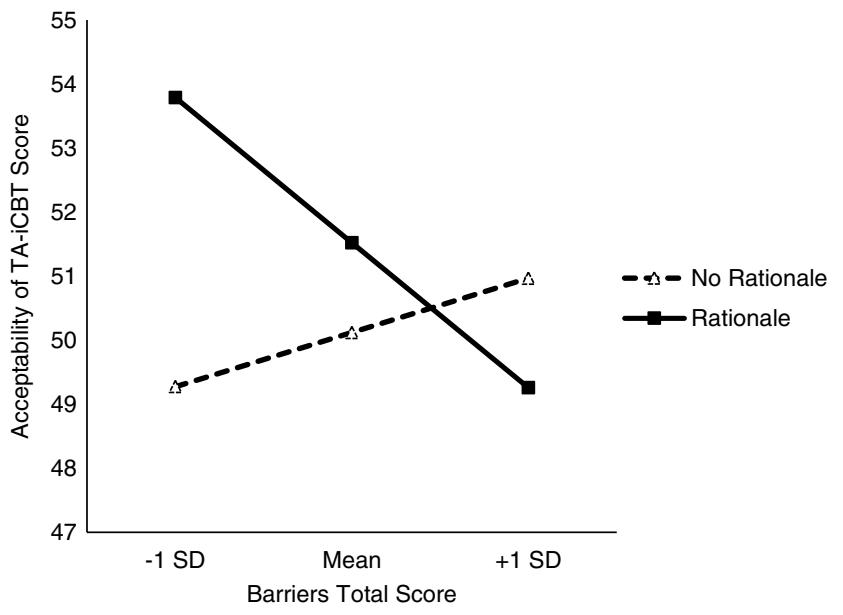

Note. $\quad$ iCBT $=$ Internet-based cognitive behavioral therapies.

Participants recruited from the university subject pool reported more barriers to treatment than participants in the community, which is interesting given that all university students have access to no-cost mental health treatment via the University Counseling Center and low-cost mental health treatment via the University Psychology Clinic. This finding is comparable to prior literature indicating that young adults endorse greater barriers to treatment than older adults (Andrade et al., 2014; Pepin et al., 2009), but inconsistent with studies finding no differences between student and community samples (Forbes et al., 2017; Segal et al., 2005). If this finding is replicated it will be important to understand why participants recruited from the university report more barriers to treatment

Figure 2

Line Graph Indicating That Stigma Significantly Moderates the Relationship Between Treatment Rationale and Acceptability Toward Therapist-Assisted iCBT

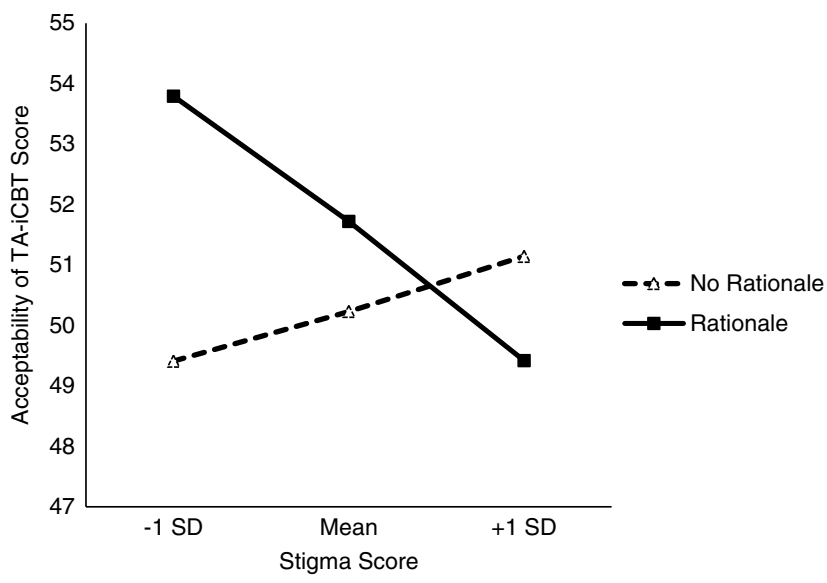

Note. $\quad$ iCBT $=$ Internet-based cognitive behavioral therapies. than participants recruited from the community-differences between university participants and community participants could reflect differences in age, accumulated wealth, or perceived resources, though further study is needed. Regardless, this finding highlights the importance of outreach to Black students about the availability of mental health treatment.

The proportion of participants in this study who indicated they would "likely" or "definitely" use iCBT (45\%) is comparable to prior literature reporting that participants would either "possibly" or "definitely" be interested in using iCBT (35\%-55\%; Choi et al., 2015; Mohr, Siddique, et al., 2010; Wootton et al., 2011) and better than other studies in which perceptions of iCBT were "poor" or "neutral" or intentions to use iCBT were low (Carper et al., 2013; Musiat et al., 2014; Travers \& Benton, 2014). Similar to previous estimates (Klein \& Cook, 2010; Mitchell \& Gordon, 2007; Neal et al., 2011; Soucy et al., 2016), a negligible proportion of our sample $(1.3 \%)$ had any experience using iCBT. Low familiarity with iCBT may breed more perception of risk and aversion, especially given the more popular option of face-to-face therapy (Mohr, Siddique, et al., 2010; Musiat et al., 2014).

Participants expressing a greater likelihood of using an iCBT program if prescribed by a health professional than if recommended by a spiritual leader or no one at all was interesting given that $73.1 \%$ of the current sample rated their religious or spiritual preference as "Important" or "Very important" to them. Studies have shown that church-based mental health promotion initiatives have significant influence on health behaviors among African Americans (Campbell et al., 2007; Peterson et al., 2002). Given that clergy in the Black religious community are often gatekeepers to broader mental health access via pastoral care and external referrals (Avent et al., 2015; Blank et al., 2002; Taylor et al., 2000), this surprising finding deserves further investigation. However, results of the study suggest that leveraging the prescriptive authority of medical professionals may be an effective method for improving treatment dissemination and access to iCBT among Black Americans.

\section{Strengths and Limitations}

This is the first experimental study to explore barriers to treatment and attitudes of acceptability for nontreatment seeking Black participants. This is important because much of the existing literature that has examined acceptability toward iCBT have used treatmentseeking samples (which may not be as generalizable to the broader population) and very few have recruited Black participants; a community that disproportionately faces barriers to treatment and may stand to benefit from the advantages afforded by iCBT (e.g., cost savings, accessibility, and reduced stigma). Furthermore, this study is the first to examine actionable strategies for improving attitudes toward iCBT among Black Americans.

Despite the study's strengths, there are limitations that warrant attention. Over $70 \%$ of participants had some level of college education, which is not surprising, given that about half of participants were recruited from the university subject pool and almost a third of participants recruited from the community were in college or had a professional degree. Unfortunately, the proportion of participants who were recruited from the community who graduated from college was not measured. This may have implications for measuring attitudes toward internet-based mental health treatments as educational attainment has been linked to mental health treatment 
seeking (Steele et al., 2007; see Broman, 2012, for evidence of the inverse relationship of education on Black American treatment seeking). Furthermore, the treatment rationale was designed for a parent study (Molloy et al., 2021) that included a demographically diverse and varied population and the primary speaker was that of a White clinical psychologist. The lack of cultural-tailoring and crossracial presentation of the speaker may have impacted acceptability for a Black participant sample. Cultural mistrust is associated with negative views and expectations of White mental health providers (Cuevas et al., 2016; Whaley, 2001a, 2001b) and research has generally supported stronger preferences for mental health treatment from racially concordant providers among Black Americans (Cabral \& Smith, 2011; Ellis et al., 2019; Malat et al., 2010). Additionally, the distinction between a treatment rationale and a brief definition, although conceptually important for providing the minimum information needed to provide an informed opinion toward a still nascent technology (i.e., iCBT), may have been perceived as functionally identical between participants in each condition. Essentially this may have reflected a comparison between an experimental condition and active control. Lastly, although attitudes toward treatments are predictive of treatment-seeking behavior (Beatie et al., 2016; Hammer \& Spiker, 2018) they do not equate to treatment-seeking behavior, and it is imperative that future research investigate actual uptake of iCBT.

\section{Future Directions}

The need to increase the diversity and inclusion of minority and underrepresented populations in the literature concerning attitudes and utilization of internet-delivered therapies is paramount. Mental health disparities persist in Black and African American communities (Gaston et al., 2016), and these communities stand to disproportionately benefit from the opportunities afforded through this novel medium. Indeed, $40 \%$ of participants in the present study reported cost being a prevailing barrier to mental health treatment with nearly half of participants endorsing more than one substantial barrier. If barriers to treatment are multifaceted, this requires a multifaceted solution. We cannot simply reduce structural barriers of cost and accessibility without also addressing attitudinal barriers such as stigma. iCBT is well-suited to address these therapeutic needs.

Furthermore, although research has widely supported the efficacy and effectiveness of iCBT interventions in reducing mental health symptoms for majority populations (Andrews et al., 2018; Hedman et al., 2012) it has largely neglected examining the efficacy and acceptability of these treatments for Black populations, save for select few studies (Jonassaint et al., 2017, 2020). Even less attention has been given to understanding the extent to which communities of color perceive the benefit of internet-delivered therapies in mitigating barriers to therapy such as stigma, lack of faith in treatment, affordability, and convenience. This is an important gap in the literature that deserves further investigation.

It would behoove researchers to further invest in the development of acceptance-facilitating interventions for iCBT. Key moderators, such as attitudinal barriers to treatment, mental health distress, and treatment history, are also poised for further investigation. Additionally, a behavioral measure of intent and use of iCBT would be informative for elucidating the link between attitudes of acceptability and treatment-seeking behavior as the two are not inherently equal (Diala et al., 2000).

Lastly, it could be argued that a deliberate attention to tailoring treatment rationales to a given audience may prove fruitful. Research has demonstrated the efficacy of culturally tailored mental health interventions for minority populations (Barrera et al., 2013; McCall et al., 2019; Rathod et al., 2018) but thus far none have been created for Black Americans regarding the use of iCBT. Investigating the potential impact of speaker identity, background, racial matching, and endorsement on iCBT treatment-seeking attitudes deserves further study for identifying the optimal delivery of treatment rationales to Black Americans, which is a highly heterogeneous group. Ultimately, for internet treatments to be effectively integrated into routine practice, they will need to achieve "equivalence in terms of clinical outcomes, efficiency in terms of resource use and costs, and acceptability of "minimal interventions" to patients and therapists" (Bower \& Gilbody, 2005, p. 11). The previous three decades have demonstrated our capacity to design, evaluate, and deploy efficacious internet-based therapies. It is now time that we devote our efforts to understanding and improving the public's desire to actually use them, especially among underserved and minority communities.

\section{References}

Ajzen, I. (1991). The theory of planned behavior. Organizational Behavior and Human Decision Processes, 50(2), 179-211. https://doi.org/10.1016/ 0749-5978(91)90020-T

Alegría, M., Canino, G., Ríos, R., Vera, M., Calderón, J., Rusch, D., \& Ortega, A. N. (2002). Inequalities in use of specialty mental health services among Latinos, African Americans, and non-Latino whites. Psychiatric Services, 53(12), 1547-1555. https://doi.org/10.1176/appi.ps.53.12.1547

Alegria, M., Lin, J., Chen, C.-N., Duan, N., Cook, B., \& Meng, X.-L. (2012). The impact of insurance coverage in diminishing racial and ethnic disparities in behavioral health services. Health Services Research, 47(3 Pt. 2), 1322-1344. https://doi.org/10.1111/j.1475-6773 .2012.01403.x

Andersson, G., Cuijpers, P., Carlbring, P., Riper, H., \& Hedman, E. (2014). Guided internet-based vs. face-to-face cognitive behaviour therapy for psychiatric and somatic disorders. World Psychiatry, 13(3), 288-295. https://doi.org/10.1002/wps.20151

Andrade, L. H., Alonso, J., Mneimneh, Z., Wells, J. E., Al-Hamzawi, A., Borges, G., Bromet, E., Bruffaerts, R., de Girolamo, G., de Graaf, R., Florescu, S., Gureje, O., Hinkov, H. R., Hu, C., Huang, Y., Hwang, I., Jin, R., Karam, E. G., Kovess-Masfety, V. . . Kessler, R. C. (2014). Barriers to mental health treatment: Results from the WHO World Mental Health surveys. Psychological Medicine, 44(6), 1303-1317. https://doi.org/10 1017/S0033291713001943

Andrews, G., Basu, A., Cuijpers, P., Craske, M., McEvoy, P., English, C., \& Newby, J. (2018). Computer therapy for the anxiety and depression disorders is effective, acceptable and practical health care: An updated meta-analysis. Journal of Anxiety Disorders, 55, 70-78. https://doi.org/10 .1016/j.janxdis.2018.01.001

Apolinário-Hagen, J., Kemper, J., \& Stürmer, C. (2017). Public acceptability of e-mental health treatment services for psychological problems: A scoping review. JMIR Mental Health, 4(2), Article e10. https://doi.org/ 10.2196/mental.6186

Avent, J. R., Cashwell, C. S., \& Brown-Jeffy, S. (2015). African American pastors on mental health, coping, and help seeking. Counseling and Values, 60(1), 32-47. https://doi.org/10.1002/j.2161-007X.2015.00059.x

Ayalon, L., \& Alvidrez, J. (2007). The experience of Black consumers in the mental health system-Identifying barriers to and facilitators of mental 
health treatment using the consumers' perspective. Issues in Mental Health Nursing, 28(12), 1323-1340. https://doi.org/10.1080/01612840701651454

Barrera, , Jr, M., Castro, F. G., Strycker, L. A., \& Toobert, D. J. (2013). Cultural adaptations of behavioral health interventions: A progress report. Journal of Consulting and Clinical Psychology, 81(2), 196-205. https:// doi.org/10.1037/a0027085

Beatie, B. E., Stewart, D. W., \& Walker, J. R. (2016). A moderator analysis of the relationship between mental health help-seeking attitudes and behaviours among young adults. Canadian Journal of Counselling and Psychotherapy, 50(3), 290-314. https://cjc-rcc-ucalgary-ca.acces.bibl.ula val.ca/cjc/index.php/rcc/article/view/2871/pdf_1

Blank, M. B., Mahmood, M., Fox, J. C., \& Guterbock, T. (2002). Alternative mental health services: The role of the black church in the South. American Journal of Public Health, 92(10), 1668-1672. https://doi.org/10.2105/ AJPH.92.10.1668

Bower, P., \& Gilbody, S. (2005). Stepped care in psychological therapies: Access, effectiveness and efficiency. Narrative literature review. The British Journal of Psychiatry, 186(1), 11-17. https://doi.org/10.1192/ bjp.186.1.11

Broman, C. L. (2012). Race differences in the receipt of mental health services among young adults. Psychological Services, 9(1), 38-48. https:// doi.org/10.1037/a0027089

Cabral, R. R., \& Smith, T. B. (2011). Racial/ethnic matching of clients and therapists in mental health services: A meta-analytic review of preferences, perceptions, and outcomes. Journal of Counseling Psychology, 58(4), 537-554. https://doi.org/10.1037/a0025266

Campbell, M. K., Hudson, M. A., Resnicow, K., Blakeney, N., Paxton, A., \& Baskin, M. (2007). Church-based health promotion interventions: Evidence and lessons learned. Annual Review of Public Health, 28(1), 213-234. https://doi.org/10.1146/annurev.publhealth.28.021406.144016

Carper, M. M., McHugh, R. K., \& Barlow, D. H. (2013). The dissemination of computer-based psychological treatment: A preliminary analysis of patient and clinician perceptions. Administration and Policy in Mental Health, 40(2), 87-95. https://doi.org/10.1007/s10488-011-0377-5

Casey, L. M., Joy, A., \& Clough, B. A. (2013). The impact of information on attitudes toward e-mental health services. Cyberpsychology, Behavior, and Social Networking, 16(8), 593-598. https://doi.org/10.1089/cyber 2012.0515

Center for Collegiate Mental Health. (2017). Center for collegiate mental health standardized data set (SDS) (pp. 1-34). Pennsylvania State University.

Choi, I., Sharpe, L., Li, S., \& Hunt, C. (2015). Acceptability of psychological treatment to Chinese- and Caucasian-Australians: Internet treatment reduces barriers but face-to-face care is preferred. Social Psychiatry and Psychiatric Epidemiology, 50(1), 77-87. https://doi.org/10.1007/s00127014-0921-1

Choi, I., Zou, J., Titov, N., Dear, B. F., Li, S., Johnston, L., Andrews, G., \& Hunt, C. (2012). Culturally attuned Internet treatment for depression amongst Chinese Australians: A randomised controlled trial. Journal of Affective Disorders, 136(3), 459-468. https://doi.org/10.1016/j.jad.2011 .11 .003

Cialdini, R. B. (2006). The psychology of persuasion. Collins Business Essentials.

Constantino, M. J., Ametrano, R. M., \& Greenberg, R. P. (2012). Clinician interventions and participant characteristics that foster adaptive patient expectations for psychotherapy and psychotherapeutic change. Psychotherapy: Theory, Research, \& Practice, 49(4), 557-569. https://doi.org/10 $.1037 / \mathrm{a} 0029440$

Cuevas, A. G., O'Brien, K., \& Saha, S. (2016). African American experiences in healthcare: "I always feel like I'm getting skipped over." Health Psychology, 35(9), 987-995. https://doi.org/10.1037/hea0000368

Cundiff, J. L. (2012). Is mainstream psychological research "womanless" and "raceless"? An updated analysis. Sex Roles, 67(3-4), 158-173. https:// doi.org/10.1007/s11199-012-0141-7
Diala, C., Muntaner, C., Walrath, C., Nickerson, K. J., LaVeist, T. A., \& Leaf, P. J. (2000). Racial differences in attitudes toward professional mental health care and in the use of services. American Journal of Orthopsychiatry, 70(4), 455-464. https://doi.org/10.1037/h0087736

Ebert, D. D., Berking, M., Cuijpers, P., Lehr, D., Pörtner, M., \& Baumeister, H. (2015). Increasing the acceptance of internet-based mental health interventions in primary care patients with depressive symptoms. A randomized controlled trial. Journal of Affective Disorders, 176, 9-17. https://doi.org/10.1016/j.jad.2015.01.056

Ellis, D. M., \& Anderson, P. L. (2020). Improving the acceptability of Internet-based cognitive-behavioral therapy among Black Americans. Open Science Framework, Pre-registration. https://doi.org/10.17605/ OSF.IO/2GYQX

Ellis, D. M., Guastello, A. D., Anderson, P. L., \& McNamara, J. P. H. (2019). How racially concordant therapists and culturally responsive online profiles impact treatment-seeking among Black and White Americans. Practice Innovations, 4(2), 75-87. https://doi.org/10.1037/ pri0000084

Forand, N. R., Barnett, J. G., Strunk, D. R., Hindiyeh, M. U., Feinberg, J. E., \& Keefe, J. R. (2018). Efficacy of guided iCBT for depression and mediation of change by cognitive skill acquisition. Behavior Therapy, 49(2), 295-307. https://doi.org/10.1016/j.beth.2017.04.004

Forbes, M. K., Crome, E., Sunderland, M., \& Wuthrich, V. M. (2017). Perceived needs for mental health care and barriers to treatment across age groups. Aging \& Mental Health, 21(10), 1072-1078. https://doi.org/10 $.1080 / 13607863.2016 .1193121$

Gaston, G. B., Earl, T. R., Nisanci, A., \& Glomb, B. (2016). Perception of mental health services among Black Americans. Social Work in Mental Health, 14(6), 676-695. https://doi.org/10.1080/15332985 .2015 .1137257

Gerhards, S. A., de Graaf, L. E., Jacobs, L. E., Severens, J. L., Huibers, M. J. H., Arntz, A., Riper, H., Widdershoven, G., Metsemakers, J. F., \& Evers, S. M. (2010). Economic evaluation of online computerised cognitive-behavioural therapy without support for depression in primary care: Randomised trial. The British Journal of Psychiatry, 196(4), 310-318. https://doi.org/10.1192/bjp.bp.109.065748

Hammer, J. H., \& Spiker, D. A. (2018). Dimensionality, reliability, and predictive evidence of validity for three help-seeking intention instruments: ISCI, GHSQ, and MHSIS. Journal of Counseling Psychology, 65(3), 394-401. https://doi.org/10.1037/cou0000256

Hayes, A. F. (2018). Introduction to mediation, moderation, and conditional process analysis: A regression-based approach (2nd ed.). Guilford Press.

Hedman, E., Andersson, E., Ljótsson, B., Andersson, G., Rück, C., \& Lindefors, N. (2011). Cost-effectiveness of Internet-based cognitive behavior therapy vs. cognitive behavioral group therapy for social anxiety disorder: Results from a randomized controlled trial. Behaviour Research and Therapy, 49(11), 729-736. https://doi.org/10.1016/j.brat 2011.07.009

Hedman, E., Ljótsson, B., \& Lindefors, N. (2012). Cognitive behavior therapy via the Internet: A systematic review of applications, clinical efficacy and cost-effectiveness. Expert Review of Pharmacoeconomics \& Outcomes Research, 12(6), 745-764. https://doi.org/10.1586/erp.12.67

Hennemann, S., Beutel, M. E., \& Zwerenz, R. (2017). Ready for eHealth? Health professionals' acceptance and adoption of eHealth interventions in inpatient routine care. Journal of Health Communication, 22(3), 274-284. https://doi.org/10.1080/10810730.2017.1284286

Hobbs, M. J., Joubert, A. E., Mahoney, A. E. J., \& Andrews, G. (2018). Treating late-life depression: Comparing the effects of internet-delivered cognitive behavior therapy across the adult lifespan. Journal of Affective Disorders, 226, 58-65. https://doi.org/10.1016/j.jad.2017.09.026

Horvath, P. (1990). Treatment expectancy as a function of the amount of information presented in therapeutic rationales. Journal of Clinical Psychology, 46(5), 636-642. https://doi.org/10.1002/1097-4679(199009)46: 5<636::AID-JCLP2270460516>3.0.CO;2-U 
Jonassaint, C. R., Belnap, B. H., Huang, Y., Karp, J. F., Abebe, K. Z., \& Rollman, B. L. (2020). Racial differences in the effectiveness of internetdelivered mental health care. Journal of General Internal Medicine, 35(2), 490-497. https://doi.org/10.1007/s11606-019-05542-1

Jonassaint, C. R., Gibbs, P., Belnap, B. H., Karp, J. F., Abebe, K. K., \& Rollman, B. L. (2017). Engagement and outcomes for a computerised cognitive-behavioural therapy intervention for anxiety and depression in African Americans. British Journal of Psychiatry Open, 3(1), 1-5. https:// doi.org/10.1192/bjpo.bp.116.003657

Klein, B., \& Cook, S. (2010). Preferences for e-mental health services amongst an online Australian sample. Electronic Journal of Applied Psychology, 6(1), 27-38. https://doi.org/10.7790/ejap.v6i1.184

Lattie, E. G., Kashima, K., \& Duffecy, J. L. (2019). An open trial of internetbased cognitive behavioral therapy for first year medical students. Internet Interventions : the Application of Information Technology in Mental and Behavioural Health, 18(September), Article 100279. https://doi.org/10 .1016/j.invent.2019.100279

Lovibond, P. F., \& Lovibond, S. H. (1995). The structure of negative emotional states: comparison of the depression anxiety stress scales (DASS) with the beck depression and anxiety inventories. Behaviour Research and Therapy, 33(3), 335-343. https://doi.org/10.1016/00057967(94)00075-U

Lovibond, S. H., \& Lovibond, P. F. (1993). Manual for the depression anxiety stress scales (DASS). Psychology Foundation Monograph. Psychology Foundation of Australia

Magaard, J. L., Seeralan, T., Schulz, H., \& Brütt, A. L. (2017). Factors associated with help-seeking behaviour among individuals with major depression: A systematic review. PLOS ONE, 12(5), Article e0176730. https://doi.org/10.1371/journal.pone.0176730

Malat, J., Purcell, D., \& van Ryn, M. (2010). Factors affecting whites' and blacks' attitudes toward race concordance with doctors. Journal of the National Medical Association, 102(9), 787-793. https://doi.org/10.1016/ S0027-9684(15)30675-1

McCall, T., Bolton Iii, C. S., McCall, R., \& Khairat, S. (2019). The use of culturally-tailored telehealth interventions in managing anxiety and depression in African American adults: A systematic review. Studies in Health Technology and Informatics, 264, 1728-1729. https://doi.org/10 .3233/SHTI190618

Mitchell, N., \& Gordon, P. K. (2007). Attitudes towards computerized CBT for depression amongst a student population. Behavioural and Cognitive Psychotherapy, 35(4), 421-430. https://doi.org/10.1017/S1352465807003700

Mohr, D. C., Hart, S. L., \& Marmar, C. (2006). Telephone administered cognitive-behavioral therapy for the treatment of depression in a rural primary care clinic. Cognitive Therapy and Research, 30(1), 29-37. https://doi.org/10.1007/s10608-006-9006-0

Mohr, D. C., Ho, J., Duffecy, J., Baron, K. G., Lehman, K. A., Jin, L., \& Reifler, D. (2010). Perceived barriers to psychological treatments and their relationship to depression. Journal of Clinical Psychology, 66(4), 394409. https://doi.org/10.1002/jclp.20659

Mohr, D. C., Siddique, J., Ho, J., Duffecy, J., Jin, L., \& Fokuo, J. K. (2010). Interest in behavioral and psychological treatments delivered face-to-face, by telephone, and by internet. Annals of Behavioral Medicine, 40(1), 89-98. https://doi.org/10.1007/s12160-010-9203-7

Mojtabai, R., Olfson, M., Sampson, N. A., Jin, R., Druss, B., Wang, P. S., Wells, K. B., Pincus, H. A., \& Kessler, R. C. (2011). Barriers to mental health treatment: Results from the National Comorbidity Survey Replication. Psychological Medicine, 41(8), 1751-1761. https://doi.org/10.1017/ S0033291710002291

Molloy, A., Ellis, D. M., Su, L., \& Anderson, P. L. (2021). Improving acceptability and uptake behavior for Internet-based cognitive-behavioral therapy. Frontiers in Digital Health, 3, Article 34. https://doi.org/10.3389/ fdgth.2021.653686

Musiat, P., Goldstone, P., \& Tarrier, N. (2014). Understanding the acceptability of e-mental health-Attitudes and expectations towards computerised self-help treatments for mental health problems. BMC Psychiatry, 14(1), Article 109. https://doi.org/10.1186/1471-244X14-109

Neal, D. M., Campbell, A. J., Williams, L. Y., Liu, Y., \& Nussbaumer, D. (2011). "I did not realize so many options are available": Cognitive authority, emerging adults, and e-mental health. Library \& Information Science Research, 33(1), 25-33. https://doi.org/10.1016/j.lisr.2010.07.015

Neighbors, H. W. (1985). Seeking professional help for personal problems: Black Americans' use of health and mental health services Community Mental Health Journal, 21(3), 156-166. https://doi.org/10 1007/BF00754731

Neighbors, H. W., Caldwell, C., Williams, D. R., Nesse, R., Taylor, R. J., Bullard, K. M., Torres, M., \& Jackson, J. S. (2007). Race, ethnicity, and the use of services for mental disorders: Results from the National Survey of American Life. Archives of General Psychiatry, 64(4), 485-494. https:// doi.org/10.1001/archpsyc.64.4.485

Newby, J. M., Mewton, L., \& Andrews, G. (2017). Transdiagnostic versus disorder-specific internet-delivered cognitive behaviour therapy for anxiety and depression in primary care. Journal of Anxiety Disorders, 46, 25-34. https://doi.org/10.1016/j.janxdis.2016.06.002

Norton, P. J. (2007). Depression Anxiety and Stress Scales (DASS-21): Psychometric analysis across four racial groups. Anxiety, Stress, and Coping, 20(3), 253-265. https://doi.org/10.1080/10615800701309279

Patel, S. R., Wheaton, M. G., Andersson, E., Rück, C., Schmidt, A. B., La Lima, C. N., Galfavy, H., Pascucci, O., Myers, R. W., Dixon, L. B., \& Simpson, H. B. (2018). Acceptability, feasibility, and effectiveness of Internet-based cognitive-behavioral therapy for obsessive-compulsive disorder in New York. Behavior Therapy, 49(4), 631-641. https:// doi.org/10.1016/j.beth.2017.09.003

Payne, J. S. (2014). The influence of secular and theological education on pastors' depression intervention decisions. Journal of Religion and Health, 53(5), 1398-1413. https://doi.org/10.1007/s10943-013-9756-4

Pepin, R., Segal, D. L., \& Coolidge, F. L. (2009). Intrinsic and extrinsic barriers to mental health care among community-dwelling younger and older adults. Aging \& Mental Health, 13(5), 769-777. https://doi.org/10 .1080/13607860902918231

Peterson, J., Atwood, J. R., \& Yates, B. (2002). Key elements for churchbased health promotion programs: Outcome-based literature review. Public Health Nursing, 19(6), 401-411. https://doi.org/10.1046/j.15251446.2002.19602.x

Pew Research Center. (2009). A religious portrait of African Americans. http://www.pewforum.org/2009/01/30/a-religious-portrait-of-african-ame ricans/

Rathod, S., Gega, L., Degnan, A., Pikard, J., Khan, T., Husain, N., Munshi, T., \& Naeem, F. (2018). The current status of culturally adapted mental health interventions: A practice-focused review of meta-analyses. Neuropsychiatric Disease and Treatment, 14, 165-178. https://doi.org/10.2147/ NDT.S138430

Rosso, I. M., Killgore, W. D. S., Olson, E. A., Webb, C. A., Fukunaga, R., Auerbach, R. P., Gogel, H., Buchholz, J. L., \& Rauch, S. L. (2017) Internet-based cognitive behavior therapy for major depressive disorder: A randomized controlled trial. Depression and Anxiety, 34(3), 236-245. https://doi.org/10.1002/da.22590

Sareen, J., Jagdeo, A., Cox, B. J., Clara, I., ten Have, M., Belik, S.-L., de Graaf, R., \& Stein, M. B. (2007). Perceived barriers to mental health service utilization in the United States, Ontario, and the Netherlands. Psychiatric Services, 58(3), 357-364. https://doi.org/10.1176/ps.2007. 58.3.357

Schappert, S. M., \& Burt, C. W. (2006). Ambulatory care visits to physician offices, hospital outpatient departments, and emergency departments: United States, 2001-2002. Vital and Health Statistics, 13(159), 1-66. Data from the National Health Survey.

Schröder, J., Sautier, L., Kriston, L., Berger, T., Meyer, B., Späth, C., Köther, U., Nestoriuc, Y., Klein, J. P., \& Moritz, S. (2015). Development of a 
questionnaire measuring Attitudes towards Psychological Online Interventions-the APOI. Journal of Affective Disorders, 187, 136-141. https://doi.org/10.1016/j.jad.2015.08.044

Segal, D. L., Coolidge, F. L., Mincic, M. S., \& O'Riley, A. (2005). Beliefs about mental illness and willingness to seek help: A cross-sectional study. Aging \& Mental Health, 9(4), 363-367. https://doi.org/10.1080/13607860500131047

Snell-Johns, J., Mendez, J. L., \& Smith, B. H. (2004). Evidence-based solutions for overcoming access barriers, decreasing attrition, and promoting change with underserved families. Journal of Family Psychology, 18(1), 19-35. https://doi.org/10.1037/0893-3200.18.1.19

Snowden, L. R., \& Pingitore, D. (2002). Frequency and scope of mental health service delivery to African Americans in primary care. Mental Health Services Research, 4(3), 123-130. https://doi.org/10.1023/A: 1019709728333

Soucy, J. N., Owens, V. A. M., Hadjistavropoulos, H. D., Dirkse, D. A., \& Dear, B. F. (2016). Educating patients about Internet-delivered cognitive behaviour therapy: Perceptions among treatment seekers and nontreatment seekers before and after viewing an educational video. Internet Interventions : the Application of Information Technology in Mental and Behavioural Health, 6, 57-63. https://doi.org/10.1016/j.invent.2016 .09 .003

Steele, L. S., Dewa, C. S., Lin, E., \& Lee, K. L. (2007). Education level, income level and mental health services use in Canada: Associations and policy implications. Healthcare Policy, 3(1), 96-106. https://doi.org/10 $.12927 /$ hcpol.2007.19177

Taylor, R. J., Chatters, L. M., \& Levin, J. (2004). Religion in the lives of African Americans. Sage Publications.

Taylor, R. J., Ellison, C. G., Chatters, L. M., Levin, J. S., \& Lincoln, K. D. (2000). Mental health services in faith communities: The role of clergy in black churches. Social Work, 45(1), 73-87. https://doi.org/10.1093/sw/ 45.1 .73

Travers, M. F., \& Benton, S. A. (2014). The acceptability of therapistassisted, internet-delivered treatment for college students. Journal of College Student Psychotherapy, 28(1), 35-46. https://doi.org/10.1080/ 87568225.2014 .854676

U.S. Department of Health and Human Services. (2001). Mental health: Culture, race, and ethnicity: A supplement to mental health: A report of the Surgeon General. U.S. Public Health Service: Substance Abuse and Mental Health Services Administration.
Venkatesh, V., Morris, M. G., Davis, G. B., \& Davis, F. D. (2003). User acceptance of information technology: Toward a unified view. Management Information Systems Quarterly, 27(3), 425-478. https://doi.org/10 .2307/30036540

Waller, R., \& Gilbody, S. (2009). Barriers to the uptake of computerized cognitive behavioural therapy: A systematic review of the quantitative and qualitative evidence. Psychological Medicine, 39(5), 705-712. https:// doi.org/10.1017/S0033291708004224

Ward, E. C., Wiltshire, J. C., Detry, M. A., \& Brown, R. L. (2013). African American men and women's attitude toward mental illness, perceptions of stigma, and preferred coping behaviors. Nursing Research, 62(3), 185-194. https://doi.org/10.1097/NNR.0b013e31827bf533

Whaley, A. (2001a). Cultural mistrust: An important psychological construct for diagnosis and treatment of African Americans. Professional Psychology, Research and Practice, 32(6), 555-562. https://doi.org/10.1037/ 0735-7028.32.6.555

Whaley, A. (2001b). Cultural mistrust and mental health services for African Americans: A review and meta-analysis. The Counseling Psychologist, 29(4), 513-531. https://doi.org/10.1177/0011000001294003

Williams, A. D., \& Andrews, G. (2013). The effectiveness of Internet cognitive behavioural therapy (iCBT) for depression in primary care: A quality assurance study. PLOS ONE, 8(2), Article e57447. https://doi.org/ 10.1371/journal.pone.0057447

Williams, M. T., Domanico, J., Marques, L., Leblanc, N. J., \& Turkheimer, E. (2012). Barriers to treatment among African Americans with obsessivecompulsive disorder. Journal of Anxiety Disorders, 26(4), 555-563. https://doi.org/10.1016/j.janxdis.2012.02.009

Wootton, B. M., Titov, N., Dear, B. F., Spence, J., \& Kemp, A. (2011). The acceptability of Internet-based treatment and characteristics of an adult sample with obsessive compulsive disorder: An Internet survey. PLOS ONE, 6(6), Article e20548. https://doi.org/10.1371/journal.pone.0020548

Young, J. L., Griffith, E. E. H., \& Williams, D. R. (2003). The integral role of pastoral counseling by African-American clergy in community mental health. Psychiatric Services, 54(5), 688-692. https://doi.org/10.1176/appi .ps.54.5.688

Received December 17, 2020

Revision received June 15, 2021

Accepted June 29, 2021 